\title{
Perioperative visual loss following transurethral resection surgery: not always a transurethral resection syndrome
}

\author{
Abdelghafour Elkoundi, MD (D) Mustapha Bensghir, PhD • Mohammed Meziane, MD • \\ Charki Haimeur, PhD
}

Received: 27 May 2016/Revised: 11 July 2016/Accepted: 18 July 2016/Published online: 29 July 2016

(C) Canadian Anesthesiologists' Society 2016

\section{To the Editor,}

Posterior reversible encephalopathy syndrome (PRES) is a rare neurological disorder, the diagnosis of which is based on clinical and abnormal neuroimaging findings. The visual loss associated with PRES may be difficult to distinguish from similar findings in transurethral resection (TUR) syndrome, resulting in diagnostic delay. We focus here on the differential diagnosis and investigation required to distinguish between these conditions. Written informed consent was obtained from the patient to publish this report.

A 67-yr-old man (height $170 \mathrm{~cm}$, weight $78 \mathrm{~kg}$ ) with a history of untreated hypertension and benign prostatic hypertrophy underwent TUR of the prostate under spinal anesthesia. Preoperative serum electrolytes and blood count were normal. In the operating room, his blood pressure (BP) was 135/85 $\mathrm{mmHg}$, and heart rate (HR) was 68 beats $\min ^{-1}$. Spinal anesthesia was administered with $12 \mathrm{mg}$ of hyperbaric bupivacaine $(0.5 \%)$ and $25 \mu \mathrm{g}$ fentanyl at the L3-4 level. The patient was placed in the lithotomy position, and the BP increased to $160 / 85 \mathrm{mmHg}$. Transurethral resection proceeded using monopolar electrocautery and $1.5 \%$ glycine irrigation solution. Forty minutes into the procedure, the patient reported the acute onset of bilateral blindness.

Apart from the visual loss, he was conscious and had no other neurological deficits. His BP was $210 / 140 \mathrm{mmHg}$, HR 90 beats. $\mathrm{min}^{-1}$, and $\mathrm{SpO}_{2} 100 \%$. The total amount of

\footnotetext{
A. Elkoundi, MD ( $₫) \cdot$ M. Bensghir, PhD · M. Meziane, MD ·

C. Haimeur, $\mathrm{PhD}$

Department of Anesthesiology and Intensive Care, Military

Hospital Med V of Rabat, Faculty of Medicine and Pharmacy of

Rabat, University Souissi-Med V, Rabat, Morocco

e-mail: abd.el.koundi@gmail.com
}

irrigation fluid absorbed was not recorded. We suspected TUR syndrome, so the surgery was stopped and the patient transferred to the intensive care unit. His serum sodium was $119 \mathrm{mEq} \cdot \mathrm{L}^{-1}$, and calculated serum osmolality was $245 \mathrm{mmol} \cdot \mathrm{L}^{-1}$.

Other conditions, such as retinal ischemia and ischemic optic neuropathy, were excluded because of a normal fundoscopic examination and the bilateral involvement. Symptoms suggestive of cerebral edema (e.g., preserved light perception; dilated, non-reactive pupils) were present. ${ }^{1}$ A computed tomography scan of the head was obtained and was negative for structural neurologic injury.

An intravenous infusion of $3 \%$ saline solution at a rate of $0.5 \mathrm{~mL} \cdot \mathrm{kg}^{-1} \cdot \mathrm{hr}^{-1}$ was started with furosemide $20 \mathrm{mg}$. His blood pressure dropped to $145 / 95 \mathrm{mmHg}$ and remained slightly above the normal range $(150 / 90$ to $170 / 95 \mathrm{mmHg})$ without further therapy. Forty-eight hours later, his vision loss persisted despite normalization of serum sodium (136 $\mathrm{mmol} \cdot \mathrm{L}^{-1}$ ).

Glycine and their metabolites (glyoxylic, oxalic acid) are major inhibitory neurotransmitters in both the retina and the central nervous system. ${ }^{2}$ Considering that the halflife of glycine is $85 \mathrm{~min}$, this mechanism seemed unlikely to be the cause of persistent visual loss. Ammonia, another metabolite of glycine, can impair vision, but the patient's serum levels were not elevated $\left(50 \mu \mathrm{g} \cdot \mathrm{dL}^{-1}\right)$. A psychiatric assessment ruled out a conversion disorder.

With other causes eliminated, we considered the diagnosis of PRES. This syndrome is characterized by headache, altered mental function, seizures, and visual disturbances. An acute increase in blood pressure is regarded as the main risk factor for PRES. ${ }^{3}$ Hypertension causes temporary impairment of autoregulation of the cerebral vasculature, leading to breakdown of the bloodbrain barrier, vasogenic edema, and endothelial 


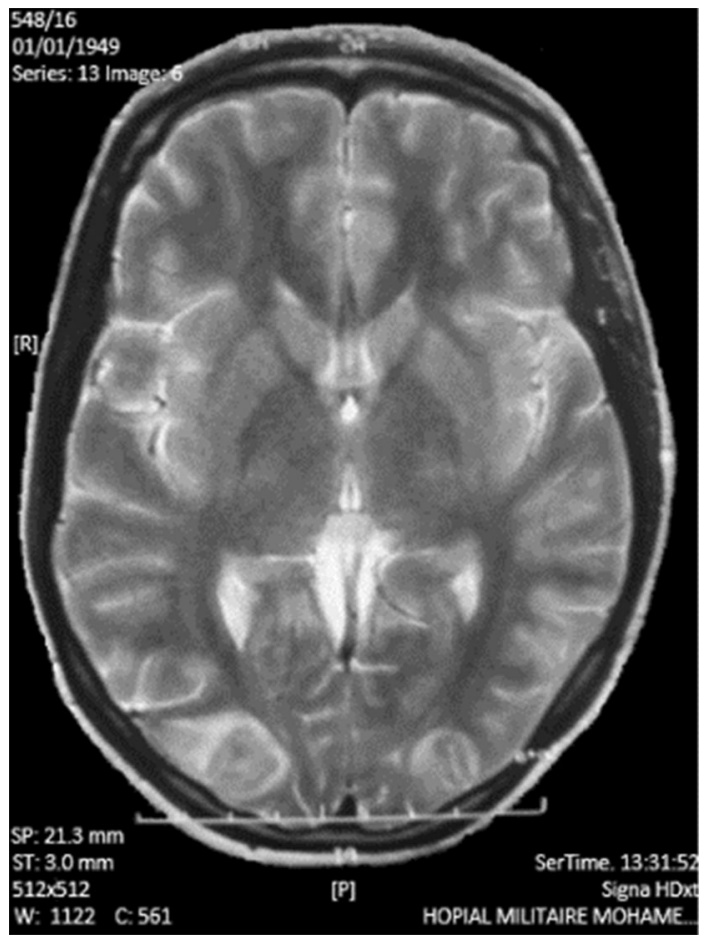

Figure Fluid-attenuated inversion recovery (FLAIR) T2-weighted magnetic resonance imaging of the brain revealed bilateral hyperintensity lesions involving the occipital white matter, which is consistent with advanced posterior reversible encephalopathy syndrome

dysfunction. ${ }^{3,4}$ Visualization of vasogenic edema involving the posterior cerebral circulation on magnetic resonance imaging is a characteristic of PRES (see Figure).
A continuous nicardipine infusion was started. The patient's BP returned to normal range, and his vision returned within six hours.

We encourage clinicians to consider PRES in hypertensive patients presenting visual loss during or after TUR surgery.

Conflicts of interest None declared.

Editorial responsibility This submission was handled by Dr. Gregory L. Bryson, Deputy Editor-in-Chief, Canadian Journal of Anesthesia.

\section{References}

1. Defalque RJ, Miller DW. Visual disturbances during transurethral resection of the prostate. Can Anaesth Soc J 1975; 22: 620-1.

2. Ovassapian A, Joshi CW, Brunner EA. Visual disturbances: an unusual symptom of transurethral prostatic resection reaction. Anesthesiology 1982; 57: 332-4.

3. Rabinstein AA, Mandrekar J, Merrell R, Kozak OS, Durosaro O, Fugate JE. Blood pressure fluctuations in posterior reversible encephalopathy syndrome. J Stroke Cerebrovasc Dis 2012; 21: 254-8.

4. Fugate JE, Claassen DO, Cloft HJ, Kallmes DF, Kozak OS, Rabinstein AA. Posterior reversible encephalopathy syndrome: associated clinical and radiologic findings. Mayo Clin Proc 2010; 85: 427-32. 